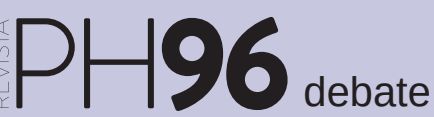

a debate Memoria democrática en la construcción de la historia y el patrimonio

| coordina Josefina Cuesta Bustillo

\title{
Compromiso democrático, patrimonio y memoria en la enseñanza de la historia
}

\author{
Emilio José Delgado-Algarra | Centro Académico y Cultural de Asia Oriental, Dpto. de Didácticas Integradas, Universidad de \\ Huelva
}

URL de la contribución <www.iaph.es/revistaph/index.php/revistaph/article/view/4303>

Agradeciendo de antemano la invitación para participar en tan interesante e imprescindible debate. Tras la lectura del resto de intervenciones incluidas hasta el momento y en relación con algunos resultados del proyecto de investigación "Educación Patrimonial para la Inteligencia Territorial y Emocional de la Ciudadanía" (EPITEC), financiado por el Ministerio de Economía y Competitividad (EDU2015-67953-P), con la cofinanciación de los fondos FEDER de la Unión Europea, voy a participar en el mismo desde el enfoque de una didáctica de las ciencias sociales comprometida y posicionándome a favor de la enseñanza de una historia con memoria donde se eduque para una ciudadanía informada, participativa, crítica y orientada a la justicia social. Así pues, desde un planteamiento de escuela entendida como motor de cambio social, se plantea como necesaria la selección, secuenciación y construcción de contenidos escolares partiendo de problemas actuales e históricos relevantes, el conocimiento cotidiano de los estudiantes (conocimientos previos y dificultades reales) y el conocimiento disciplinar que debe saber el docente para poder enseñar (ESTEPA, 2007). Como indica Aróstegui (2004), podemos hablar de tres fases de la memoria oficial en España: memoria de la exaltación, que abarca desde el final de la Guerra Civil española (1939) hasta el fallecimiento de Francisco Franco (1975); memoria de la reconciliación, que abarca desde la muerte de Francisco Franco hasta mediados de los 90 del siglo XX; y memoria de la reparación, que abarcada desde mediados de los 90 del siglo XX hasta la actualidad.

En plena etapa de memoria de la reparación, y ante la ruptura parcial que se produjo con el franquismo durante el proceso de transición a la Democracia, resulta necesario que en el contexto escolar se ofrezca al alumnado las herramientas necesarias para buscar, analizar y comprender la existencia de resquicios de la dictadura en el contexto urbano. La actividad no se encuentra exenta de dificultades, entre las que podemos resaltar la existencia de una serie de puntos ciegos en la Ley de Memoria Histórica que afectan al reconocimiento de algunos posibles resquicios del franquismo; puntos ciegos que introduce Rina Simon en el debate de este número. Es por ello que la enseñanza de una historia con memoria debe contar con orientación de un docente suficientemente formado al respecto $y$, en la medida de posible, involucrado en equipos para la recuperación de las memorias. Considerando la memoria como un asunto que genera controversia y volviendo a la importancia de la formación docente de cara a hacer frente a temáticas controvertidas en el aula, las investigaciones de Waterson (2009) y Yeager y Humphries (2011) destacan que a una buena parte del profesorado no se le ha enseñado a enseñar, a lo que se suma el hecho de que siga existiendo cierto temor a abordar temas controvertidos por temor a la reacción de la comunidad educativa. En este sentido, parece existir un tabú que es necesario superar desde la propia escuela, institución que tiene la corresponsabilidad de educar en democracia a las nuevas generaciones de ciudadanos. En otras palabras, superar dicho tabú desde la escuela resulta imprescindible para potenciar las funciones normalizadora y reparadora de la enseñanza de la historia y de las ciencias sociales en relación con las memorias en conflicto.

En consonancia con algunas de las aportaciones que se han sumado a lo largo de este debate, y desde un enfoque multidimensional, podríamos definir la memoria como "un recuerdo cargado de valores subjetivos relacionados con los momentos conflictivos de nuestra historia 


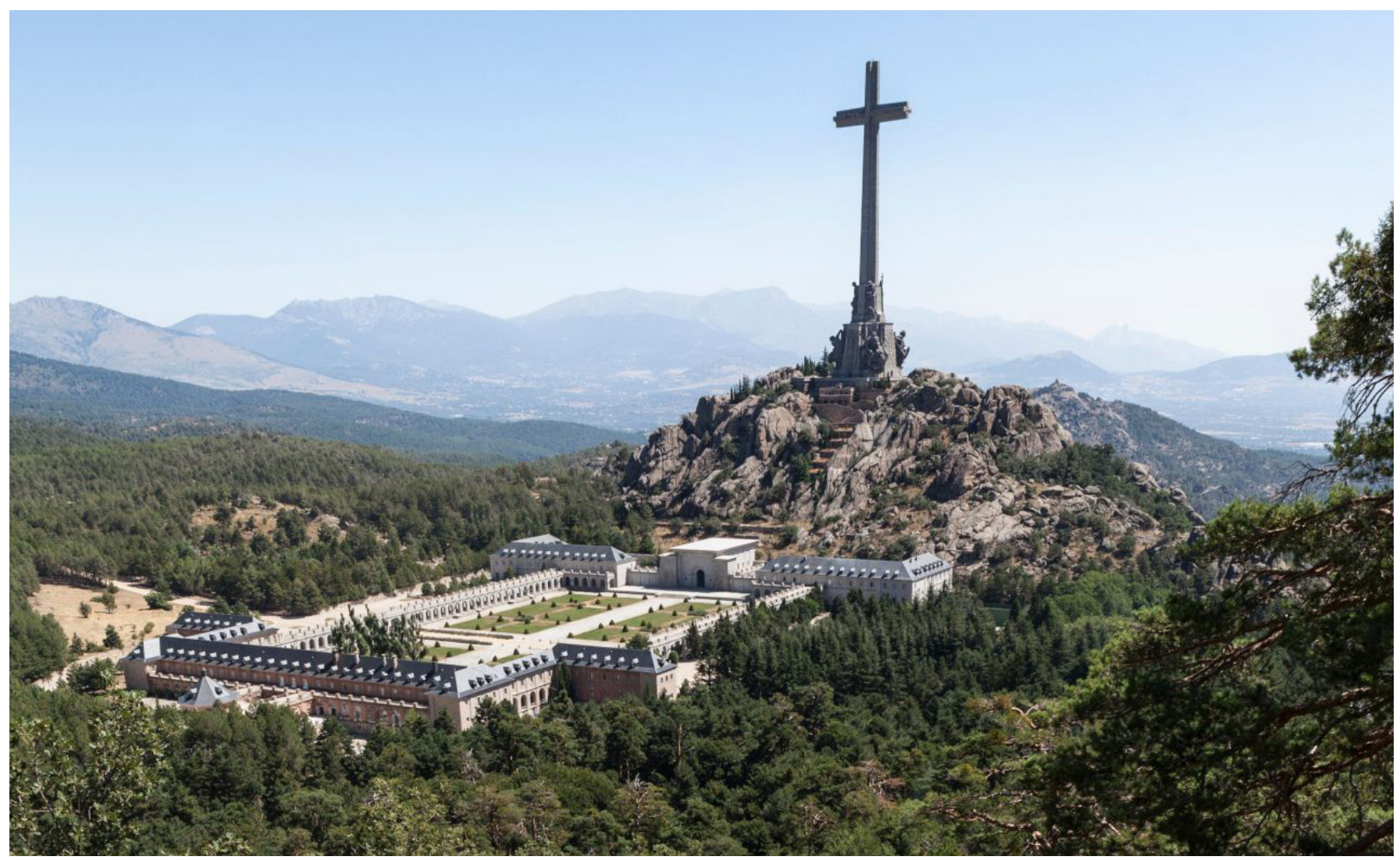

El Valle de los Caídos | foto Lahcène Abib pour Le Parisien Week End (LANGLOIS, 2018)

reciente, definiéndose a raíz de la experiencia personal de cada individuo en el seno de un grupo social determinado" (DELGADO-ALGARRA; ESTEPA-GIMÉNEZ, 2016: 523). De este modo, para analizar y comprender las memorias en el contexto escolar y en relación con la enseñanza de la historia, entran en juego 5 dimensiones claramente diferenciadas y a las que resulta necesario atender (CUESTA, 2011): individual, social, histórica, conflictiva y selectiva. Un ejemplo paradigmático de problemática donde se entrelazan patrimonio y memoria dentro de contexto español es el del Valle de los Caídos, en torno al cual, antes de la retirada de los restos de dictador, existen dos posturas irreconciliables: la de los que lo entienden como un lugar de paz y de oración por los caídos durante la Guerra Civil; y la de los que lo ven como medio propagandístico del régimen dictatorial de Franco. Con idea de establecer una analogía compara- tiva donde quede constancia de que este tipo de polémicas no es exclusiva de España, en contexto japonés, nos encontramos con espacio del Santuario Yasukuni, en torno al cual, los recuerdos de la guerra han contribuido a la internacionalización del conflicto mnemónico en tres etapas que van desde las disputas internas en torno a la labor de control llevada a cabo por el sistema de aprobación de los libros de texto hasta la internacionalización de la polémica suscitada desde 2001 al autorizarse textos escolares de historia revisada que, pese a ser de uso minoritario, rechaza la enseñanza de una historia considerada "no japonesa" (DELGADO-ALGARRA, 2018).

En líneas generales, la investigación ha puesto de manifiesto el potencial que la recuperación de las memorias tiene para la enseñanza de una historia que contribuye 


\section{a debate Memoria democrática en la construcción de la historia y el patrimonio \\ | coordina Josefina Cuesta Bustillo}

al compromiso con la democracia. El patrimonio, igualmente, se convierte en portador de memorias en conflicto. En este sentido, para fomentar desde la escuela el compromiso ciudadano con la Democracia, en términos metodológicos, se considera que, en la enseñanza de la ciencias sociales y de la historia, es importante partir de problemas socioambientales relevantes de la actualidad y fomentar la comprensión y el compromiso con los mismos a través de la historia. Para que esto sea posible, el docente debe tener una formación específica que le permita atender a las controversias sociohistóricas que puedan surgir o que se puedan plantear dentro del aula; ya que, en líneas generales, la atención a las memorias (como fuente de la historia) en sus cinco dimensiones, contribuye a la educación para una ciudadanía democrática, informada y participativa, comprometida con el presente, conocedora de su pasado y consciente de su futuro.

\section{BIBLIOGRAFÍA}

- ARÓstegul, J. (2004) La historia vivida. Madrid: Alianza Editorial, 2004

- CUESTA, R. (2011) Historia con memoria y didáctica crítica. Con-ciencia Social, n. ${ }^{\circ} 15,2011$, pp. 15-30

- DELGADO-AlgARRA, E. J.; ESTEPA-GIMÉNEZ, J. (2016) Ciudadanía y memoria histórica en la enseñanza de la historia: análisis de la metodología didáctica en un estudio de caso en ESO. Revista de Investigación Educativa, n. ${ }^{\circ} 34$ (2), 2016, pp. 521-534

- DELGAdO-AlgARRA, E. J. (2018) Education for Citizenship and Social Studies in Japan: Historical Evolution and Challenges for a Cosmopolitan Identity. En PINEDAALFONSO, J. A.; DE ALBA-FERNÁNDEZ, N.; NAVARROMEDINA, E. (ed.) Handbook of of Research on Education for Participative Citizenship and Global Prosperity. United States: IGI Global, 2018

- ESTEPA, J. (2007) Investigando las sociedades actuales e históricas. Proyecto curricular Investigando Nuestro Mundo (6 -12). Sevilla: Diada Editora, 2007

- LANGLOIS, B. (2018) Espagne: la dépouille de Franco bientôt

retirée de son mausolée? LeParisien, 20 de octubre de 2018 $<$ http://www.leparisien.fr/international/espagne-la-depouillede-franco-bientot-retiree-de-son-mausolee-13-08-2018-78519 84.php> [Consulta: 29/01/2019]

- WATERSON, R. A. (2009) The examination of pedagogical approaches to teaching controversial public issues: Explicitly teaching the Holocaust and comparative genocide. Social Studies Research and Practice, n. ${ }^{\circ} 4$ (2), 2009, pp. 1-24

- YEAGER, E.; HUMPHRIES, E. K. (2011) A Social Studies teacher's sense making of controversial issues discussions of race in a predominantly white, rural high school classroom. Theory and Research in Social Education, n. ${ }^{\circ} 39$ (1), 2011, pp. 92-134 